\title{
Mood and Ambiances: A Narration of Expressive Forms and Urban Emotions
}

https://doi.org/10.21814/uminho.ed.51.2

Fabio La Rocca

LEIRIS (Laboratoire d'Études Interdisciplinaires sur le Réel et les Imaginaires Sociaux), Faculté des Sciences du Sujet et de la Société, Université Paul Valéry Montpellier 3,

Montpellier, France https://orcid.org/0000-0001-7635-5666 fabio.la-rocca@univ-montp3.fr

\section{Abstract}

Everyday urban life is invented and reinvented. As a result, the unique relationship we establish with places and spaces is the product of the effects of the territorial environment from an emotional and affective point of view. The lived space supports a collective identification with the development of a diversity of sensitive practices that constitute the variety of atmospheres and a form of narration of the urban and social scene that emphasises atmospheric qualities and urban tonalities. We focus on the sensitive qualities of space and the correlation of a phenomenology of sense that emphasises an ontology of coexistence and being with space, producing a narration of ambiances and atmospheres arrangement to understand the perceptions of urban emotions.

Keywords

city, emotions, imaginary, Stimmung, urban ambiances 
Things see me as much as I see them. - Paul Valéry, Cahiers 1894-1915 - Tome V (1994)

The city, and its socio-urban daily life, is invented and reinvented through the practices and uses of its multiple places and spaces. As a result, symbolic and affective effects are produced, characterising the lived experience through a collective identity generated by the sensible qualities and variety of ambiances encountered. That produces a potential ontological narrative of urban life as a space created through its sensory qualities, forming a kaleidoscope of sensations, where emotions must be understood as a way in which to identify an experience amplified by moods within a space. These urban moods express how a city is thought about, felt, and expressed. A theoretical approach, emphasising the quality of urban environments, shall be employed to address the urban phenomenon. "Setting the ambiance of a space", to cite Jean-Paul Thibaud (2013), is a way in which to focus on a kind of "poetics of space. To reference a famous analysis by Pierre Sansot (1973), uncovering the resonances permeated in urban daily life that can be decoded and deciphered through wanderings, flaneries, through the city. These last two actions must be thought of as a tangible method employed by a sensory observer who, through their own subjective sensory projection in space, can bring out the qualities of a space, the various moods encountered within this moment of passage. These passages can be accomplished when approached as a sensible flaneur, forming the corollary of a perspective on what we feel and resent. A kind of sensory engagement, the flaneur, in their own right, can experience emotions and sensations through their senses. That is how a framework of urban moods is formed, which can be multifaceted, depending on the sense(s) employed, whether smell, hearing or touch, composing a certain polyphony of urban ambiances. It is worth noting that Russian theorist Mikhail Bakhtin introduced the concept of "polyphony" as an approach to literary theory and the aesthetics of a novel. However, it can be adapted to the context of this paper and the urban experience, as a polyphonic space experienced through a plurality of lived and felt expressions. A space that arises through various expressive modalities formed by mood and ambient qualities, giving rise to an aesthetic of urban narration. That is a new communicative form of inhabiting a city, in which the space's sensory qualities and its ambiances are emphasised. Thus, the city is expressed through the senses and new senses constructed through experience. While cities, as a construction, are founded on the premise of always having something new to provide, it could subsequently be said that the collective narration of urban ambiances, as a specificity of the ordinary daily experience, is constructed and reconstructed by a certain sensory dynamism formed by the endless ways in which one can feel and position oneself. 


\section{The Immersive Approach of the Flaneur-Researcher}

In this understanding of urban storytelling and its moods, scientific guidance is provided through the act of immersion. Spatial immersion, through which urban sensibility is discovered and perceived, is a subjective experience that can be compared to plunging oneself into the urban atmospheres of spaces, thus producing a vision of the imaginary of cities where the city is, parallelly, both the subject and object of this imaginary construction. That means that when one is immersed in one space, detecting and capturing its moods allows for a mosaic of impressions to be created through a sensory process that is observed, smelt, and felt. Here, when reference is made to this sensitive or sensory experience, it is important to emphasise the key role played by the senses and the meanings assigned to them in subsequent perceptual descriptions produced. Therefore, a phenomenological immersion aiming to perceive to describe, following Sansot's (1986) "layers of meaning", characterising the urban imaginary. A body immersing in one space provides the opportunity to demonstrate the perceptions of what it encounters (phenomenologically) during such an immersion. This approach is achieved when the position of a metropolitan flaneur is adopted, one capable of drawing attention to the sensory experiences a city can provide. Beyond being a literary figure, a flaneur - this figure of a purposeless, yet philosophical, metropolitan flaneur - made famous by various authors such as Charles Baudelaire, Honoré de Balzac, Louis Huart, Franz Hessel and Walter Benjamin, must be considered a method of discovery and observation employed in a sensory approach to ambiances.

In fact, the sociologist-flaneur is a position adopted, a perspective from which to determine what the city can provide in sensory terms and then render the experiences encountered perceptually, through images, smells, noises, sounds, and surfaces touched, all of which contribute to a carnal relationship being created with the urban space that is both mediated and unmediated (in the sense of the mediums employed). The urban spaces are discovered sensorially by walking through as a flaneur, allowing for the real and imaginary urban setting to be perceived through sensory experiences.

In adopting Maurice Merleau-Ponty's (1964) theory of the phenomenology of perception, it becomes clear that all the senses are employed in any act of perception and that in a spatial immersion conducted through wandering, the various sensory dynamics of the city can be felt and experienced through the very act of deciphering them in order to build a vision of what is being perceived. The flaneur's approach is directly related to this 
decipherment with a poetic sensitivity (once again, as is Sansot's 1973 approach). It allows the city to be perceived through a process that collects ordinary details (Kracauer, 2006) and fragments (Benjamin, 1939/1986) to construct a narration of this text - the city as the object/subject of observation - from the angle of its moods. In wandering to seek, thus, with a purpose, a kind of "impressionistic" sensibility can be built to shape concepts, as in the theory of Georg Simmel (1903/2013). Perceptual impressions, which are the object of the construction of a vision of urban reality - which is no longer totalising, rather focussed on everyday microscopy, emphasising the multiple sensory fragments encountered (smells, sounds, images, movements...) - will, on the whole, form a significant structure through which urban ambiances can be interpreted. This wandering approach as a method establishes a phenomenological circumstance of sensitive apprehension of space considering, according to the analysis of Raymond Ledrut (1973), that the city is the signifier and the signified and that it expresses and is expressed, it is sign and meaning. Therefore, our impressions through the attitude of immersion by wandering will provide a meaning of the urban experience by highlighting the tonal characteristics, which are forms and expressions of an ontology of the city. Grasping meanings and senses is the objective of spatial immersion, where the researcher, as a flaneur, employs sensory observation to identify expressive situations and give the city a voice. Subjective wandering, in this case, also calls for subjectivity in the description provided, still echoing the approach of Sansot (1973), by building an "ordinary knowledge" (Maffesoli, 1985) of the city and its ambiances, which expresses the idea that the urban environment can no longer be confined to a purely functional construction. On the other hand, the emphasis must be placed on space's narration fuelled by the imaginary layered over everyday structures. Here, the researcher-flaneur brings out the sensory impressions of an approach to ambiances as both a form and expression of the urban imaginary. Urban space, moreover, "is not a pre-established and self-evident object of research" (Grosjean \& Thibaud, 2001, p. 7). Therefore, various approaches develop forms of understanding adapted to the theoretical perspective. Capturing ambiances is thus the approach selected; the purpose of a researcher-flaneur who, looking through sociological glasses, acts as a detective, unveiling the urban experience through these layers of meaning with which the city is endowed. This sociological wandering seeks to enable a sensory reading of the city, perceiving it as multiple sensory experiences. Walter Benjamin's (1939/1986) specific analysis determined that the figure of the flaneur moves sensitively through the labyrinth of the city in order to restore an overarching meaning, and therefore to conduct 
the sociological task of bringing its details to life. This procedure is about feeling while wandering. It allows the pages of this open book, the city is, to be read and the meanings of each sensory element generated by each ambiances to be deciphered. In essence, this philosophical metropolitan wandering employed, with purpose, and as a method through which to conduct research, aims to explore and decipher urban environments, the researcher being placed as an observer as a means to render urban forms legible.

\section{Expressions}

Maintaining a perspective of sensitive dynamism while exploring an urban environment means, to some extent, situating oneself in what is defined, according to an expression coined by Michel Maffesoli (2010), as "geosociology": that is, a form of an ingrained social bond. As we see it, this rooting is nourished by constructing a particular type of societal geography anchored in the feelings, emotions and experiences that give meaning to places and their production of ambiances. It is a construction of a "surface hermeneutics", specific to the sensory theory in Kracauer, Simmel and Benjamin (Füzesséry \& Simay, 2008), which can be interpreted as a particular physiognomy of the gaze on the social to deepen the dimension of ambiances in the mosaic that is urban reality. This action takes us, as a detective, to penetrate through a careful look aiming at discovering new sensibilities to understand this "magma of everyday life" (Kracauer, 2006) and its ambient components.

Within this ambiance of everyday urban life, "pieces of life" in Simmel's (1981) words are detected, coming together to form a significant unit of social places, spaces of emotions, and even sensitive spaces. This spatial sensitivity is thus condensed into the "flesh of the world" (Merleau-Ponty, 1964). It allows us to bring out all the energy that dynamises the space through sensory transmissions, such as sound and the societal practices of spatial immersion like skateboarding, parkour acrobatics and other cultural dynamics that merge the human body with the flesh of the city in a tactile manner. This flesh opens up in the location where the body is immersed, in a spatiality that can be defined as "topographical" in the sense of a sensitive being's environment being where socio-spatial relationships are forged. This type of sensitivity, inspired by the theory of perception of Merleau-Ponty (1964), points towards a spatial configuration from within, a "flesh" being that must then be penetrated by devoting itself to a space. That, in turn, points to the preponderance of a lifeworld, or Lebenswelt, in phenomenology, a world that can be experienced first-hand, a living world 
where feelings of "I am my body" predominate, also illustrating, simultaneously, the idea of "I am my space".

The focus is a perception of the urban world to which meaning and value are conferred, made up of the collective inhabited space where humans must find a sense of harmony between the landscape and themselves. This harmonisation is formed by the various sensory actions taken as part of the relationship between humans and spaces and the generated perceptions of spaces through images, sounds, smells and noises. It is how such an organic relationship is formulated, taking place through the action of walking, wandering through these places. In carrying out this action, our senses are called upon, working together to sketch out a map of sensory stimuli, incorporating moods into the application of ambiances. That also demonstrates a reliance of individuals who remain in urban spaces on said spaces, one conditioned by the various ambient imperatives. In their daily lives, individuals consummate their existence by immersing themselves in the various sensory spaces and places of a metropolis. This action, in turn, works to add value to architecture and existentialism through "energy ethics" (Joron, 2010, p. 17) and the intensification of the will to live. One could even illustrate this as a vibrant and creative will expressing exaltation, and a Dionysian joy encountered in urban life in the multiple ways of experiencing space and constructing tonal effects, thus giving a particular mood to a place through the expression of experience. There is a conception of the multiplication of urban situations, where energy and vitality express observable social life. One example is sound and festive street productions, and an energetic reading represents a way of understanding the city in motion - an expressive method of setting the ambiance of a space.

Under the banner of "ontology of the street" (La Rocca, 2016), we can see the festive spirit's typicity and the sound environment that makes many locations in Naples, London, Rio de Janeiro so particular. There the mood (though reliant on the music) is an expression of the lived experience, the land itself acquires a specific intensity, a "mood-inducing power" (Thibaud, 2013) expressed by the transformation of the "street into a party" (Sanmartin et al., 2019). It is to be understood as one of the sensory methods specific to creating ambiance. A festive atmosphere generated using sound is also ephemeral, where space is pure external perception, from a Kantian perspective; that is to say, it is to be thought of as a condition in which an experience becomes possible. From this perspective, by focusing on sound if the space is always "already there", we can bring out the sensory characteristics of such a space and the organic nature and perceptible 
ways of fusion between individuals and space street music has. As such, the often-spontaneous intensity of these opportunities to dance and party (very characteristic of Brazilian streets, for example, particularly the energy in Rio and expressiveness in São Paulo) will mark a territory, transforming it into an expressive lived experience that contributes to aestheticising the atmospheric quality of the socio-spatial environment.

Moreover, inhabiting space here signifies a strategic way to think about and describe the transformations concerning society's real complexity, our perceptions and how we feel (Di Felice, 2010, p. 17). The city, in this sense, must be thought of as a medium formed by an assortment of existential places where collective practices lend strength and vigour to the urban imagination, which is structured by its sensory qualities, moods and ambiances.

\section{Mood Ambiances}

When spatial essences and societal energies are captured by combining these atmospheric feelings and expressive moods, they become a method of feeling based on mood ambiances. In employing a sensitive thought process, it is common practice to reflect on the notions of atmosphere, mood and ambiance as an aesthetic whole, which, in turn, forms a way to feel spaces. The idea of the atmosphere, which has been around for many years, particularly in German philosophy thanks to the invaluable initiatory contribution made by Gernot Böhme, operates with more and more specificity when conducting phenomenological analyses of urban spaces. It has been the result of it being combined with ambiance theory, therefore aiming to put into perspective the qualities of the affective moods manifested in spaces. An urban atmosphere in which we immerse ourselves could therefore be said to result from this existing aesthetic relationship with space: the aisthetik, to use the word coined by Böhme (2001/2020), of spatial immersions accounting for how space affects us and how we affect it in our way, by experiencing and creating situations. The result is an "aesthetic of sensory experience", still following the theoretical perspective of Böhme (2001/2020), illustrating the quality of aesthetics as feeling and experiencing, and therefore of a connection with the Stimmung into which individuals plunge themselves, and within which individuals and spaces are also mobile. In this dimension, what can be perceived as an atmosphere is, in fact, the knowledge provided by the senses, felt as a result of having harmonised with the expression of a Stimmung. Martin Heidegger (1927/1986) explained this understanding as "affective mood" within a Dasein structure and, therefore, as the foundation 
of experience. Within Heidegger's perspective, the human being is then positioned in the world through an affective principle that specifies their act of being in the world, the fact that we exist in the world at all. Moreover, Bruce Bégout's (2021) analysis on the concept of ambiance shows how Heidegger's approach to this "access to the world" contradicted a type of philosophy that did not take into account this type of experience, therefore relegating the Stimmung "to the realm of everyday things with no value" (Bégout, 2021, p. 58). However, moods do indeed represent an "ontic" everyday experience, which is therefore made up of the same qualities of everyday life, of living in and through urban space being the circumstances applied.

Though Heidegger is often referenced with this notion, there is also a psychological perspective of the term originated from Johann Georg Sulzer in 1771, the latter having focussed on emotional experiences according to musical metaphors. In 1790, Kant provided a philosophical definition of the Stimmung as a harmonious agreement between imagination and understanding in the process of knowledge in his Kritik des Urteilskraft (Critique of Judgement). This notion contains a semantic richness that refers to its definitions as affective moods, ambiance and even atmosphere. It is how space resonates with its "affective" nature. Affective here is used in the dual sense of a space that affects the individuals within it, and also of an affection (in the sense of feeling) able to produce an emotional space. The result is an "affectology", an idea expressed through Alain Mons' (2013) analyses in which the atmospheric qualities of urban spaces are expressed in the production of sensitive, or "affectological" areas, individualising a city in the way in which it influences the senses and its moods. The idea of Böhme (2001/2020) about conceptualising the atmosphere as a sensitive experience can now be better understood: that is, the atmosphere being that something that "affects us emotionally".

Consonance can be found between the notions of Stimmung and atmosphere, in which a disposition of being sensitive to the atmospheres emanated by a certain place under certain circumstances can be developed. There is this predisposition to urban intonation where individuals are contaminated taken by and into atmospheres in a kind of flotation, as expressed by Böhme (2001/2020), where a spatial mood is considered to be suspended in the air.

While the philosophical discussion surrounding the meanings of atmosphere and Stimmung is, of course, too broad to be discussed in this paper, the importance of these sensitive qualities of space are put into perspective 
here in order to illustrate the importance of ambiances in gaining an understanding of urban realities, and therefore of the mood properties of socioaesthetic situations perceived through observations and feelings.

On returning to Merleau-Ponty (1964) phenomenology, a carnal aptitude for atmospheric moods can be considered, which resonates with the affective forms generated in how space is experienced. It is also worth noting that ambiance can never be separated from these practices, which means that ambiance takes place and is felt and, above all, as clearly indicated by Thibaud (2015, p.17), the specificity of the atmosphere is linked to the affective dimension.

\section{Temporary Affective Zone}

This specificity demonstrates the importance of this disposition being affected in urban spaces. In his definition of Dasein, Heidegger already demonstrated how openness to the world presupposes a Stimmung; therefore, an affection defined in Heideggerian (1927/1986) lexicon as Befindlichkeit - the ability to feel a situation from an ontological perspective. Circumstances are faced in which the immersive capacity of our bodies must be considered, which, by merging with space, feels (and consequently produces) various moods. When contrasted with the important contribution made by psychoanalyst Ludwig Binswanger (between 1930-1960), who, in the wake of Heidegger's phenomenological theory, in addition to that put forward by Husserl, proposed a Daseinsanalysis (a comprehensive existential analysis), his analysis of "thymic space" (Der gestimmte Raum), qualified by mood and "being-attuned", is therefore put into perspective, particularly regarding the reflections made herein. Beyond the deep therapeutic roots of this approach, Binswanger's theory seems relevant because it correlates beings with spatiality, and therefore a thymic emotional disposition could be understood as being affected. That originates in sensory qualities, or "directions of meaning", in the theory of Binswanger's (1933/1989) thymic spaces, where beings find themselves in spaces loaded with meaning via corporeality, which feeds their various sensory receptors. While ambiances form part of the multiplicity of lived everyday experiences, a sensory narration of urban environments can be sought in sensory areas that can be qualified as "temporary affective zones" (using the well-known name, "temporary autonomous zone", coined by Hakim Bey in 1991). Temporary affective zones are expressions of ambiances and moods that express feelings; emotions that emanate into the populated space and resonate from the perceived space in which an ephemeral experience is had. In urban 
aesthetics, and therefore the expression of moods, these temporary autonomous zones can be understood through the concept of "atmospherology", introduced by Italian philosopher Tonino Griffero (2010). It highlights the feelings within an ambiant environment and the influence of the perception that characterises the relationship between humans and spaces. This idea can be applied to urban situations where a focus is placed on emotional intensities. The emotional, atmospheric imperative represents an attraction within these areas, condensing the energetic relationship created with the urban atmosphere. Again, urban sounds can be taken as an example, as they condense the idea of an affective and emotional zone where such a place is modified and everything within it. Considering an observation of a festive moment, for example, it is made unique by the kinaesthetic attraction felt and seen. The music, the ambient sonority resonates in space and creates a specific atmosphere due to the senses stimulated and vibrations in unison, which are characteristic of musical situations in emotional areas of Rio de Janeiro, in particular, where a fusion of emotional or cognitive sensations, or even resonances, are established between the human body and the urban body through the development of a way in which to identify with one another. Identifying a certain method emotional states can be activated, with empathy characterising the vibrant atmosphere in these "zones of affective autonomy" built between bodies, sounds, architecture, lights and other sensory components. A sensory mood is ultimately characterised by the qualities of the sensations felt in a space, enveloped by these surroundings, denoting stimulation of the senses. Many relationships exist between the emotions - and affects -, the sound and the ambiance of sound environments, illustrated by various cognitive, psychological and aesthetic studies. Here, however, the connection with spatiality predominates, that is, how music played in one street in Rio, for example, settles and creates a vibrant atmosphere that transforms spatiality into an area of emotional intensity, consequently creating a particular affectology. Regarding sounds, the rhythm of everyday life in these areas and their lived temporality can also be cited. An interesting example of this could be the famous Avenida Paulista in São Paulo, an area of attraction which in its daily nature, is a pure trigger of a nervenleben, to quote Simmel (1903/2013), with its noises, its sounds, its visual reflections of the overhanging architecture and the swift impressions made by movements. The avenue can denaturalise itself so that it may be re-enchanted at the weekend, when it transforms into a pedestrian area, the space opening up to be occupied by the bodies of city dwellers. It is transformed into a place of shared sensory experience. The resulting festivities make up a period of vibrant intensity when the street becomes a stage, open to countless possibilities spanning music, theatre, 
games, sports, acrobatics and street food, to name but a few. An intensity of emotions is subjectively experienced as individuals immerse themselves in this atmosphere, in an area open to expressiveness transformed into shared, collective emotion in a feeling of togetherness that changes the vision of this space and its architecture.

The emotions perceived here, which have been transmuted from the street's functional nature (a traffic-filled avenue lined with commerce, tourism, etc.), match emotions experienced in situations encountered. As a result, two concepts can be gained from the aestheticisation of reality, one which focuses on the relationships of individuals in spaces, and the other of individuals with others, accentuating the sensitive qualities that determine any lived experience and expressions of the affective moods of various urban situations connoting mediated and unmediated experiences. "Mood"-based experiences can also be demonstrated via areas of olfactory intensity, in the districts of Seoul, for example, thanks to its characteristic street food. That is particularly true at night, in Myeong-Dong, where twinkling lights and smells of culinary specialities intoxicate the crowd in an atmosphere where true harmony is achieved using Eugène Minkowski's (1995) terminology understood as "vibrating in unison" with the ambiance. In Seoul, this vibration is created by a phenomenology of taste and smell, which, here, represent a "tuning into an ambiance", as Hubertus Tellenbach would say (1985; also encompassing Daseinsanalysis). In his book, Goût et Atmosphère (Taste and atmosphere), Tellenbach (1968/1985) also demonstrates the importance of atmosphere and how the senses of smell and taste should be thought of as means through which "the subject merges with the world" (p. 25).

Thus, the force of immersion in the atmospheric specificities of these "zones" can be understood through several examples, as can the way in which beings are affected by a certain "atmospheric aura" (Tellenbach, 1985, p. 44) in which they are enveloped, which also particularises the mood felt and experienced in each of these multiple expressive situations. As a result, any atmosphere is characterised by the situation experienced and the intensity of its mood, forming a kind of emotional emanation that conditions individuals and the existential environments within the urban fabric.

\section{An Urban Aura}

Urban environments thus become an expression of a process of atmospheric filtering. As a result, humankind's conception is strictly related to their situational experience of any space. Particular places, spaces and territories in 
a city become expressive to beings who wish to inhabit a social dimension, through their actions and presence, affectivity and attachment to situational "zones" of urban complexity, via a multiplicity of forms, attitudes and aesthetic rituals that place our senses at the centre, attributing meaning to the fact that a city exists in all its spatial sensory peculiarities. The presence and visibility of individuals within the architectural and spatial planning of cities helps attribute meaning environments, consecrating them as "lococentric". The importance of a place, of a street, is predisposed. Each is a scene within which individuals will exist and from life will emerge through expressive moods. This idea also stems from a perception of mood radiating through locations by creating a sort of auratic process in which each place, each situation, with its specific atmospheres and moods, has an aura. Tellenbach (1985) had already introduced the concept of "aura" in his psychological approach to atmospheres, and Böhme's (2001/2020) proposal of the aesthetics of atmospheres should be understood as a change in the perception of places influenced by moods. An "urban aura", one might say, in conjunction with the theory of Walter Benjamin (1939/1986), exists in the dimension of an "immediacy of sensory presence" that can be felt when present in a space. According to Böhme (2001/2020), corresponding with the aesthetics of atmospheres could be considered to generate an affective, emotional provision that must be associated with the fusional relationship between a being and a space. An effective and affective aura can be triggered in urban wanderings where, to cite Benjamin (1923/1979), who gained inspiration from Baudelaire: "to feel the aura of a thing is to confer upon it the power to look up" (p. 200). Thus, beings look up at their surroundings in order to feel and experience the modal qualities of the environment within which they find themselves, immersing themselves in a dimension of aesthetic perception where the disposition "to feel" is connected to smells, noises, sounds and surrounding images which, under determined circumstances, can also make up a synesthetic urban landscape. From a perspective of Benjaminian reflection, this would be somewhat like a dreamlike landscape, a dream world.

Within this system employed to interpret the auratic urban space, a relation of "mediance" (Berque, 2000) can also be detected, conceived as an individual's particular relation to the environment. This relationship can be regarded through how humans inhabit the world and how our physical bodies participate in absorbing the expressive tones of space. It is understood here that this auratic capacity of the sensitive space of cities is proposed as a factor of sensitive transmutation and, therefore, of aesthetic perception. It could be suggested that to feel a space is to modify perceptions encountered upon immersion in multiple urban situations: a mood - an affective, emotional bath. 
Therefore the city is conceived as a platform of singular expressions and scenographies, denoting ways to experience a space. The urban space is built up like a fragmented matrix of heterogeneous tectonic plates generating and mixing multiple atmospheres. Aesthetic actions then strive to establish contact with the environment while creating opportunities for shared experiences, testifying to a social presence and visibility and a way of existing in an affective, emotional location. With a focus on existence ex sistere - according to its etymology - presence, or Dasein, is, therefore, to be outside oneself, clearly indicating a projection. Beings project themselves into space, creating their existence in this immersion. Drawing on Heidegger's (1927/1986) theory, we are confronted with a double ontology: the ontology of man and that of space. Thus, beyond its existence, space as such, created and modelled from an urbanistic and functional point of view, is the medium through which it gives life to collective energy through practices, appropriations and the multiple symbolic forms of social presence. According to Böhme's (2001/2020) vision here, atmospheres must be considered as spaces tinged by the presence of things and people, or "environmental constellations imbued with their ecstasies" (p. 167). Besides, if space has an ecstatic structure that relates strictly to Heidegger's (1927/1986) idea of Dasein, it can be believed to arise similarly from an ecstatic structure in so far as a being is thrown into the world and given a mood (Gestimmt). Space is present and important, providing the possibility of being filled with "meaning" by the multiple practices of everyday life. A qualitative, auratic or creative spatiality is one of the essences attributed to urban space. It is qualitative and creative in its ability to be open to all possibilities of being edified by practices and transformed by moods expressed and already there. It is auratic in that it is a dimension of a spatial atmosphere and a mood that can be felt. Therefore, assonance can be established between a being able to perceive, with its capacity for sentience (perceiving through the senses in Latin) and space. Thus, a tangible reality can be established between this perceiving being and a space, their symbolic union contributing to establishing an atmosphere. In short, - and also in agreement with the ideas of Böhme (2001/2020) on aura/atmosphere relations - the concept of a space being auratic is specific to an envelopment in meaning. It is a trans-immersion into specific situations experienced in spaces through Stimmung as a tuning mechanism, and if Heidegger's (1927/1986) perspective is maintained, reciprocity between the being and the situation within which it is present. As such, they become one in what is called an emotional experience of space, with a unitary shaping of perceptual and affective qualities in urban moods. To some extent, this idea is also present in the reflection of Simmel (1912/1988) on Landscape Philosophy, where he 
indicates the qualities of Stimmung. On the other hand, attention must also be drawn to the fact that, as the analysis of François Laplantine (2018) illustrates, the atmosphere is common in a scene in which we find ourselves and therefore presupposes a sharing of the senses (p. 59).

Throughout daily metropolitan life, one has to immerse oneself in the urban interstices to scrutinise, observe and assess the great variety of sensory qualities available and ways of being in space. Relative beings, resulting from the intense communications between spaces and individuals, a person's essence will be born from their gestures and attitudes towards sharing multifaceted emotional spaces that produce atmospheres - aesthetic situations. Upon returning to Simmelian ideals, a Lebensphilosophy of the world of space is encountered, in which space is conferred with meaning, values and meanings by the various collective aesthetic actions.

For example, in this conception, one can imagine how sounds, lights and music represent atmospheric codifiers, revealing a kind of magic relating to the sensory experience of a lived, intoned space. The creation of sound captures devices, sound installations and playing with lights in urban locations can be regarded as properties attributed so that these spaces can be felt - ways to release their ecstatic energy by creating sensory paths that allow us to live in, to touch the space. A sensory imaginary is then created, generating a connective, affective, emotional participation in a situation of intimacy with a place, in particular spatial locations.

It is clear that this set of reflections deeply question existential spatiality in the various registers within which they are appropriated. From the perspective of imaginary reliance, a vitalist impulse can work in urban spatiality, where various existential expressions create an atmospheric setting that provides information about the climatological imaginary of our cities. These atmospheres and situations are qualities specific to urban life and the construction of an energetic spirit felt in the affective emotions of spatial atmospheres. In a climatological analysis proposed of the contemporary sensitive city, urban effervescence and tonal expressions replace concepts that determine urban life, the atmosphere representing the quality of a sensitive world or leading to the sensory existence, as Emanuele Coccia (2010) says. A city represents a continuous process of experiences felt, from which space provides multiple possible conditions and openings through which to express lived experiences. 


\section{Acknowledgements}

This work is supported by national funds through FCT - Fundação para a Ciência e a Tecnologia, I.P., under the project UIDB/00736/2020.

\section{References}

Bégout, B. (2021). Le concept d'ambiance. Seuil

Benjamin, W. (1979). Charles Baudelaire (J. Lacoste, Trans.). Payot. (Original work published 1923)

Benjamin, W. (1986). Paris, capitale du XIX siècle. Le livre des Passages (J. Lacoste, Trans.). Cerf. (Original work published 1939)

Berque, A. (2000). Médiance, de milieux en paysage. Belin.

Bey, H. (1991). T.A.Z.: The temporary autonomous zone. Automedia.

Binswanger, L. (1970). Analyse existentielle, psychiatrie clinique et psychanalyse. (R. Lewinter, Trans.). Gallimard.

Binswanger, L. (1998). Le problème de l'espace en psychopathologie. (C. Gros-Azorin, Trans.). Presses Universitaires du Mirail. (Original work published 1933)

Böhme, G. (2020). Aistétique. Pour une esthétique de l'expérience sensible (M. Kaltenecker \& F. Lemonde, Trans.). Les presses du réel. (Original work published 2001)

Coccia, E. (2010). La vie sensible (M. Rueff, Trans.). Édition Payot \& Rivage. (Original work published 2010)

Di Felice, M. (2010). Paesaggi post-urbani. La fine dell'esperienza urbana e le forme communicative dell'abitare. Bevivino.

Fernandes, C. S., La Rocca, F., \& Barros, F. M. (2019). Beco das Artes: Festas, imaginários e ambiências subversivas na cidade do Rio de Janeiro. Revista Ecopos, 22(3), 140-165. https:// doi.org/10.29146/eco-pos.v22i3.27389

Griffero, T. (2010). Atmosferologia. Estetica degli spazi emozionali. Laterza.

Grosjean, M., \& Thibaud, J.P. (2001). L'espace urbain en méthode. Éditions Parenthèses.

Heidegger, M. (1986). Être et temps (F. Vezin, Trans.). Gallimard. (Original work published 1927) Joron, P. (2010). La vie improductive. Georges Bataille et l'hétérologie sociologique. PULM.

Kant, I. (1846). Critique du jugement (J. Barni, Trans.). Librairie Philosophique de Landrange. (Original work published 1790)

Kracauer, S. (2006). L'histoire. Des avant-dernières choses. Stock. 
La Rocca, F. (2016). Ontologie de la rue. Les Cahiers Européens de l'Imaginaire, 8, 238-241.

Laplantine, F. (2018). Penser le sensible. Pocket.

Ledrut, R. (1973). Les images de la ville. Anthropos.

Maffesoli, M. (1985). La connaissance ordinaire. Précis de sociologie compréhensive. Libraire des Méridiens.

Maffesoli, M. (2010). Le temps revient. Formes élémentaires de la postmodernité. Désclée de Brouwer. Merleau-Ponty, M. (1964). Phénoménologie de la perception. Gallimard.

Minkowski, E. (1995). Le temps vécu. PUF.

Mons, A. (2013). Les lieux du sensible. Villes, hommes, images. CNRS Éditions.

Sansot, P. (1973). Poétique de la ville. Meridiens Klincksieck.

Sansot, P. (1986). Les formes sensibles de la vie sociale. PUF.

Simmel, G. (1981). Sociologie et épistémologie (1884-1918). PUF.

Simmel, G. (1988). Philosophie du paysage. In La tragédie de la culture et autres essays (S. Comille \& P. Ivernel, Trans.; pp. 229-244). Rivages.

Simmel, G. (2013). Les grandes villes et la vie de l'esprit, suivi de sociologie des sens (J.-L. VieillardBaron \& F. Joly, Trans.). Petite Bibliothèque Payot. (Orginal work published 1903)

Tellenbach, H. (1985). Goût et atmosphère (J.Amsler, Trans.). PUF. (Original work published 1968)

Thibaud, J.P. (2013). Donner le ton aux territoires. In P.-L. Colon (Ed.), Ethnographier les sens (pp. 235-255). Édition Petra.

Thibaud, J.P. (2015). En quête d’ambiances. Éprouver la ville en passant. MétisPresses. 